[Highlight]

\title{
两性凝胶电解质中的离子通道: 通往全固态超级电容器
}

\author{
刘鸣华
}

(国家纳米科学中心, 北京 100190)

面对日益增长的能源需求, 超级电容器因其 高运行寿命和高功率密度成为理想的选择 ${ }^{1}$ 。而凝 胶电解质由于它在构建固态超级电容器时兼具有 电解质、隔膜、粘合剂的作用而成为关键技术材

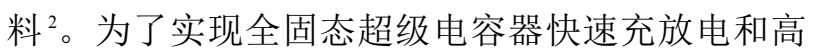
稳定性的需求, 发展兼具高离子电导率、优良机 械强度和保水性能等诸多优势的新型凝胶电解 质, 是当前该领域的重要科学问题。其核心和关 键在于如何在凝胶电解质中构建有序离子通道以 及理解其内在电化学机制 ${ }^{3}$ 。

面对这个挑战, 中国科学技术大学吴长征教授 课题组基于两性凝胶电解质 PPDP(聚(丙基磺酸盐二
甲基铵丙基甲基丙烯酰胺))有序两性基团形成独特 的离子通道, 将其成功应用于高效全固态超级电 容器。近期的 Nature Communications 杂志 ${ }^{4}$ 以 A zwitterionic gel electrolyte for efficient solid-state supercapacitors 为题, 报道了该团队的突出进展。

同步辐射软 X 射线近边吸收谱证实了两性凝 胶电解质在外加电场的情况下两性基团具有有序 性, 能够形成独特的离子通道以有利于凝胶电解 质中盐离子的传输 ${ }^{5}$ 。同时, 每个两性基团可以与 8 个水分子结合形成水化层, 使电解质 PPDP 具有 良好的保水特性 ${ }^{6}$ (见图 1)。不仅如此, 聚两性电解 质会因为通过 dipole-dipole相互作用在两性基团间
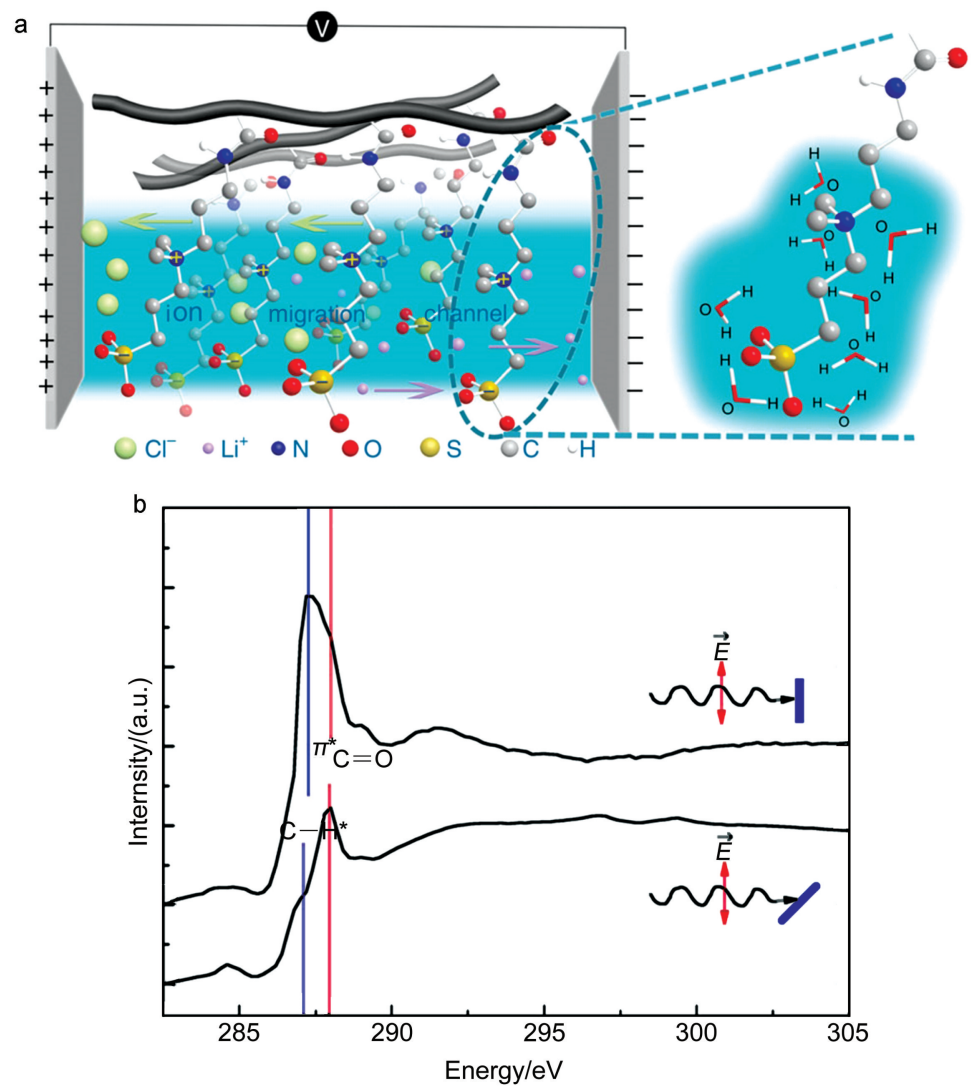

图 1 两性 PPDP 凝胶电解质在外电场下的示意图

(a) 当PPDP 凝胶电解质在应用于电极材料上时, 外界电场会使得它形成离子通道; 同时, PPDP 会因为它的两性基团和水分子之间产生的 明显水化作用而具有很好的保水能力。(b) PPDP样品在外加电场后的 C 的 $K$ 边 X 射线近边吸收谱 
形成物理凝胶, 确保了聚两性电解质在形成凝聚后 能够有一定的机械强度。构建的石墨烯基全固态超 级电容器, 在 $0.8 \mathrm{~A} \cdot \mathrm{cm}^{-3}$ 的电流密度下, 实现了 $300.8 \mathrm{~F} \cdot \mathrm{cm}^{-3}$ 的比容量, 并且电流密度增大 25 倍之 后, 仅有 $14.9 \%$ 的比容量损失, 达到了目前石墨烯 基全固态超级电容器的最优值。构建有序离子通道 为设计新型高效能源存储器件提供了新思路。

\section{References}

(1) Peng, X.; Peng, L. L.; Wu, C. Z.; Xie, Y. Chem. Soc. Rev. 2014,
43, 3303. doi: 10.1039/C3CS60407A

(2) Lu, X. H.; Yu, M. H.; Wang, G. M.; Tong, Y. X.; Li, Y. Energy Environ. Sci. 2014, 7, 2160. doi: 10.1039/C4EE00960F

(3) Wang, G. M.; Lu, X. H.; Ling, Y. C.; Zhai, T.; Wang, H. Y.; Tong, Y, X.; Li, Y. ACS Nano 2012, 6, 10296. doi: 10.1021/nn304178b

(4) Peng, X.; Liu, H. L.; Yin, Q. Wu, J. C.; Chen, P. Z.; Zhang, G. Z.; Liu, G. M.; Wu, C. Z.; Xie, Y. Nat. Commun. 2016, 7, 11782. doi: 10.1038/ncomms11782

(5) Li, Z. R.; Zhang, L.; Resasco, D. E.; Mun, B. S.; Requejo, F. G. Appl. Phys. Lett. 2007, 90, 103115. doi: 10.1063/1.2709506

(6) Wang, T.; Wang, X. W.; Long, Y. C.; Liu, G. M.; Zhang, G. Z. Langmuir 2013, 29, 6588. doi: 10.1021/1a401069y 